\title{
EDITORIAL
}

\section{Philosophy and psychiatry: problems of clinicians and problems of life}

\author{
Dan J. Stein (iD \\ SA MRC Research Unit on Risk \& Resilience in Mental Disorders, Department of Psychiatry and Neuroscience Institute, University of Cape \\ Town, Cape Town, South Africa.
}

Psychiatry raises key philosophical questions. Psychiatric classification systems raise ontological questions about diagnostic thresholds (have we have optimally divided conditions from health, and from one another?) and validity (do our particular diagnostic criteria optimally reflect the phenomenology of psychopathology, and its underlying causal mechanisms?). Psychiatric case formulations raise epistemological questions about the strength of studies of causal mechanisms in psychiatric disorders, and about how best to integrate work on biological, psychological, and societal mechanisms. Psychiatric treatments raise ethical questions about when such interventions should be provided, and about whether some treatment modalities are more appropriate; while such decisions rely on the evidence base, they also require engagement with patients' values.

Fortunately, work at the intersection of psychiatry and philosophy has significantly expanded in recent decades. Professional organizations and journals have been initiated, substantive textbooks of philosophy and psychiatry have been published, and a range of research at this intersection is under way. ${ }^{1,2}$ Such work has grappled with questions such as the definition of mental disorder, with the value of the biopsychosocial model of mental illness, and with a range of ethical questions in the field. While some psychiatrists have likely been appreciative of this body of work, others may have questioned whether academic writing at the intersection of psychiatry and philosophy is relevant to their daily work in the clinical or research context.

I would suggest that work on philosophy and psychiatry may be particularly useful in helping to walk a line between accounts of psychiatry that are either overly hagiographic (seeing the field as one in which science has gradually accumulated, with steady progress in diagnosis, etiology, and treatment) or overly critical (seeing the field as entirely lacking in scientific knowledge, and focused only on maintaining particular power structures). In Philosophy of Psychopharmacology, I argue that a "classical position" which sees

Correspondence: Dan J. Stein, UCT Department of Psychiatry, Groote Schuur Hospital, Anzio Road, Observatory, Cape Town, 7925, South Africa.

E-mail: dan.stein@uct.ac.za

Submitted Jul 30 2021, accepted Jul 30 2021, Epub Oct 182021. psychiatry as similar to physics or chemistry runs the risk of scientism and reductionism, while a "critical position" which sees psychiatry as merely one more narrative runs the risk of skepticism and cynicism. ${ }^{3}$ It is useful for clinicians and researchers to appreciate how much we have learned about mental illness, but also how much more remains to be learned.

The practice of psychiatry also raises some of the "big questions" and "hard problems" of life. Patients may struggle with a range of conflicts and choices, raising moral questions about how best to live their lives. Patients may also struggle with questions about their goals and purposes, raising the issue of the meaning of life. The psychiatrist Jerome Frank argued that patients often present clinically with "demoralization," and that psychotherapy then aims at the restoration of morale. Indeed, a range of existential and humanistic clinicians have considered these kinds of questions and their intersection with psychopathology and psychotherapy. More recently, the field of positive psychology has emphasized the importance of resilience and hope, and a parallel literature on positive psychiatry has emerged.

Philosophy has long focused on the "big questions" and "hard problems" of life, and so offers a range of rich resources for helping psychiatrists and patients address such issues. Aristotle was a polymath with a keen appreciation of psychopathology and many other fields, and provided philosophical lessons which have ongoing relevance. Spinoza, Hume, Dewey, and Jaspers, among others, were also remarkably prescient, with their writing often foreshadowing current work in cognitive-affective neuroscience and psychotherapy. While some analytic philosophers have argued that the question of the meaning of life is meaningless, there has also been a growing body of work in this area. ${ }^{4}$ Some have even argued for the establishment of a field of "philosophical counseling," which uses the philosophical literature to assist clients in resolving their personal issues.

I would suggest that philosophical work on the "big questions" and "hard problems" of life may be particularly

How to cite this article: Stein DJ. Philosophy and psychiatry: problems of clinicians and problems of life. Braz J Psychiatry. 2022;44:227-228. http://dx.doi.org/10.1590/1516-4446-2021-0033 
useful in helping to develop a balanced approach, characterized by practical wisdom, that facilitates individual and societal flourishing. In Problems of Living, I note that Western and Eastern philosophical traditions have emphasized the value of balance, and argue that this metaphor is useful in guiding us in our everyday life and clinical work. ${ }^{5}$ Along these lines, such work helps us walk a line between accounts of life that are either overly optimistic (with our world the best of all possible worlds) or overly pessimistic (with our world the worst of all possible worlds). Drawing on philosophers such as Dewey, we can develop an "integrative position," which acknowledges how difficult life can be for ourselves and our patients, but which also appreciates how awe-inspiring life is, and which encourages our efforts to further improve ourselves and our world.

\section{Disclosure}

The author has received research grants and/or consultancy honoraria from Johnson \& Johnson, Lundbeck, Sanofi, Servier, Takeda, and Vistagen.

\section{References}

1 Fulford KW, Davies M, Gipps R, Graham G, Sadler J, Stanghellini G, et al. Oxford handbook of philosophy and psychiatry. Oxford: Oxford University Press; 2013.

2 Sadler JZ, van Staden W, Fulford KW. Oxford handbook of psychiatric ethics. Oxford: Oxford University Press; 2015.

3 Stein DJ. Philosophy of psychopharmacology: smart pills, happy pills and pepp pills. Cambridge: Cambridge University Press; 2008.

4 Metz T. Meaning in life: an analytic study. Oxford: Oxford University Press; 2013

5 Stein DJ. Problems of living: perspectives from philosophy, psychiatry and cognitive-affective science. Cambridge: Elsevier; 2021. 